\begin{tabular}{|l|c|c|}
\hline \multicolumn{2}{|c|}{ DJS Vol. 38 (2017) 194- 209} \\
\hline 1969 & Delta Journal of Science & \\
\hline Research Article & Available online at & \\
\hline
\end{tabular}

\title{
Anticancer, Antimicrobial and DFT Studies of Novel Synthesized Series of $\alpha$-aminophosphonate Compounds Containing 3-amino-4(3H) quinazolinone moiety
}

\author{
Mohamed F. Abdel-Megeed ${ }^{1}$, Mohamed K. Awad ${ }^{1}$, Mahmoud F. Abdel-Aal' ${ }^{1}$, FatenM.Atlam ${ }^{1}$ and \\ Hend A. Hekal ${ }^{1}$ \\ ${ }^{1}$ Chemistry Department, Faculty of Science, Tanta University, Tanta, Egypt
}

Abstract: A novel series of Diphenyl (aryl) (4-oxo-quinazolin-4(3H)-ylamino) methyl phosphonates (1-4)is obtained in high yields from the reactions of 3-amino-4 $(3 \mathrm{H})$-quinazolinone with different aromatic aldehydes and triphenylphosphite in the presence of cupper trifillate as a Lewis acid catalyst. The structures of the synthesized compounds are confirmed by IR, ${ }^{1} \mathrm{H}$ NMR, and El-mass spectral data. The synthesized compounds show high antimicrobial activities against Gram-negative, Gram-positive bacteria and fungi at low concentrations $(2.5-10 \mathrm{mg} / \mathrm{mL})$. Also, they show significant cytotoxicity anticancer activities against liver carcinoma cell line (HepG2). The quantum chemical calculations are performed using density functional theory (DFT), with the B3LYP hybrid functional with 6-31G + (d) basis set to study the effect of the molecular and electronic structure changes on the biological activity of the investigated compounds. The calculations show that the electron-withdrawing substituent increase the biological activity of the $\alpha$-aminophosphonate compounds more than the electron donating group which is in a good agreement with the experimental results. Finally, the quantum chemical parameters confirmed with MEPs are able to describe the biological activity of the investigated compounds.

Key words: Quinazoline derivatives, $\alpha$-aminophosphonate, Anticancer activity, Antimicrobial activity, Quantum chemical parameters, DFT calculation, Computational chemistry.

\section{Introduction:}

Quinazolines are the derivatives of benzopyrimidine ring system which are used in medicine because of their wide spectrum of biological activities for resemblance of Pyrimidine nucleus. It is known and well documented in the literature that there is a connection between wide spectrums of biological activities with the molecules having quinazoline moiety [1]. Hence quinazoline-4(3H)-one is a lead compound for designing potential bioactive agents. Quinazolinones possess a broad spectrum of biological and pharmacological activities such as hypotensive, anticancer, anti-HIV, anti-inflammatory, analgesic, antiviral, ant tubercular, antimicrobial, anti-bacterial [2$11]$, etc. On the other hand considerable interest has been focused on the synthesis of $\alpha$-aminophosphonates, because of their structural analogues of the corresponding $\alpha$-amino acids and transition state mimics of peptide hydrolysis [12].Various uses of $\alpha$-amino phosphonates as antimicrobial, antioxidant, antitumor, antiviral [13-19] and enzyme inhibitors [20-22] have been discovered. 
Computer-aided drug design is a significant component of rational drug design, and is becoming more relevant [23]. The design of pharmaceutical drugs is an extremely complex and still not completely understood process [24]. Computational chemists combine their knowledge of molecular interactions and drug activity together with visualization techniques, detailed energy calculations, geometric considerations, and data filtered out of huge data bases, in an effort to narrow down the search for potent pharmaceutical drugs.Density functional theory (DFT) has been a shooting star in theoretical modeling, so they have been applied to a wide range of chemical problems. A survey of the literature revealed that DFT has a great accuracy in reproducing the experimental values for the geometry, dipole moment, vibrational frequency, etc. $[25,26]$.

Due to various types of biological activity found in Quinazoline derivatives, the present work is aimed at synthesize new $\alpha$ aminophosphonatecompoundscontainingquinazolin e moiety through three components reaction of carbonyl compounds, amine and dialkylphosphite in an organic solvent via one pot Mannich-type reaction [27], followed by studying their antimicrobial activities and the in vitro anticancer activities against liver carcinoma cell line (HepG2).Also, the work is aimed at using density functional theory (DFT) in studying the effect of the molecular and electronic structure changes on the biological activity of the investigated compounds and comparing the resulted data with the experimental data of these compounds.

\section{Computational details}

The molecular structures of the investigated compounds were optimized initially with AM1 semi empirical method so as to speed up the calculations. Then fully re-optimizations of the investigated molecules are performed using DFT (density functional theory) with the Beck's three parameter exchange functional along with the LeeYang-Parr non local correlation functional
(B3LYP) [28-30] with 6- 31G+d basis set which is implemented in Gaussian 03 program package [31]. This approach is shown to yield favorable geometries for a wide variety of systems. This basis set gives good geometry optimizations.

Quantum chemical parameters obtained from the DFT calculations which may be used to explain the biological activity of the $\alpha$-aminophosphonate compounds are the energy of the highest occupied molecular orbital (EHOMO), the energy of the lowest unoccupied molecular orbital (ELUMO), the energy gap $\Delta \mathrm{E}$, (ELUMO-EHOMO), the dipole moment (DM), ionization potential (IP), electron affinity (EA), electronegativity $(\chi)$, chemical potential $(\mu)$, the hardness $(\eta)$, the softness $(\sigma)$, the electrophilicity index $(\omega)$, the maximum electron flow from donor to the acceptor $(\Delta \mathrm{Nmax})$, the molecular volume (MV) and the sum of the total negative charges on the molecule (TNC). The concepts of these parameters are related to each other [32-37].

\section{Results and discussion}

\subsection{Synthesis of $\alpha$-aminophosphonates (1-4).}

The reaction of 3-amino-quinazolin-4(3H)one with various aromatic aldehydes such as (benzaldehyde, p-nitrobenzaldehyde, phydroxybenzaldehyde, and p-chlorobenzaldehyde) and triphenylphosphite in the presence of cupper trifillate $\mathrm{Cu}(\mathrm{OTf}) 2$ as a Lewis acid catalyst in dichloromethane (DCM) at room temperature was investigated (Scheme 1). 


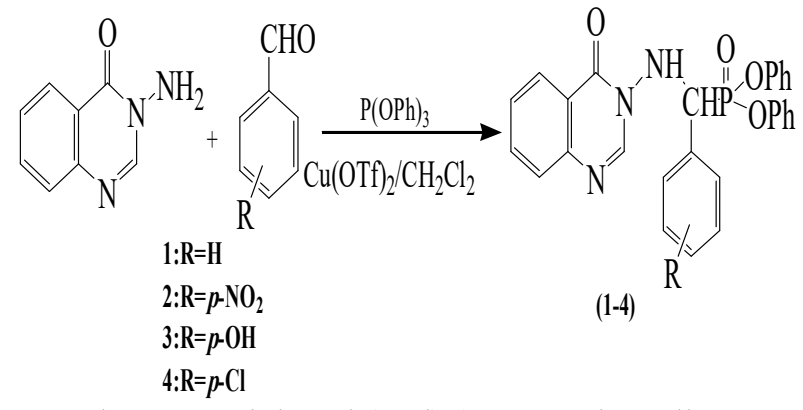

Scheme 1: Diphenyl (aryl) (4-oxo-quinazolin-

4(3H)-ylamino) methyl phosphonates (1-4)

The structures of $\alpha$-aminophosphonate compounds (1-4) are confirmed byIR, 1H NMR, and El-mass spectroscopy. The FT-IR spectrum of compounds (1-4)arecharacterized by the appearance of an absorption bands at $1327-1387 \mathrm{~cm}-1$ which are due to the symmetric stretching vibration of $\mathrm{P}=\mathrm{O}$ group. The bands appeared at 1011-1022 cmlareattributed to $v$ (P-O-C), the bands appeared at 755-778 $\mathrm{cm}-1$ are due to $v(\mathrm{P}-\mathrm{CH})$, the bands located within1603-1624cm-1are due to $\mathrm{C}=\mathrm{N}$ group, while the bands absorbed at $1649-1693 \mathrm{~cm}-$ 1 are due to $\mathrm{C}=\mathrm{O}$ group, and finally, $\mathrm{NH} / \mathrm{OH}$ group absorbed at 3443-3446cm-1, (Table 1).

The 1H-NMR (DMSO) spectrum of compounds 1-4 is characterized by the appearance of singlet signals resonated at $9.29-9.69 \mathrm{ppm}$ is due to $\mathrm{NH}$ proton, and the appearance of doublet signals resonated at5.30-5.95ppm is due to $\mathrm{CH}-\mathrm{P}$ proton, while the protons due to phenyl group resonated as multiplet in the $6.92-9.01 \mathrm{ppm}$ region. Finally, the appearance of singlet signal resonated at $10.40 \mathrm{ppm}$ is due to $\mathrm{OH}$ proton of compound 3, (Table 2).

The fragmentation pattern of compound 1 is shown in scheme 2.The mass spectrum of 1 is characterized by a molecular ion peak $(\mathrm{M}+)$ that appeared at $\mathrm{m} / \mathrm{z}=483$ and its base peak appeared at $\mathrm{m} / \mathrm{z}=105$ due to the frequent $(100 \%)$, On the other hand, the fragmentation pattern of compound 2 is shown in scheme 3.The mass spectrum of 2 is characterized by a molecular ion peak $(\mathrm{M}+)$ that appeared at $\mathrm{m} / \mathrm{z}=528$ and its base peak appeared at $\mathrm{m} / \mathrm{z}=105$ due to the frequent $(100 \%)$.

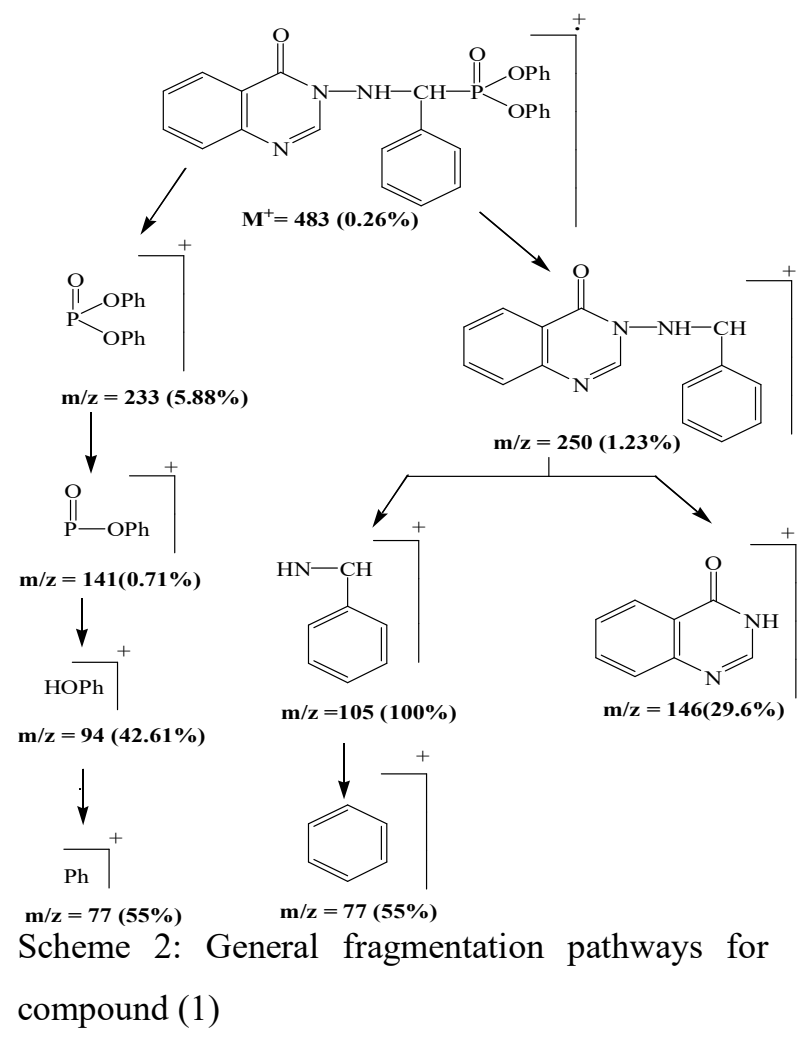




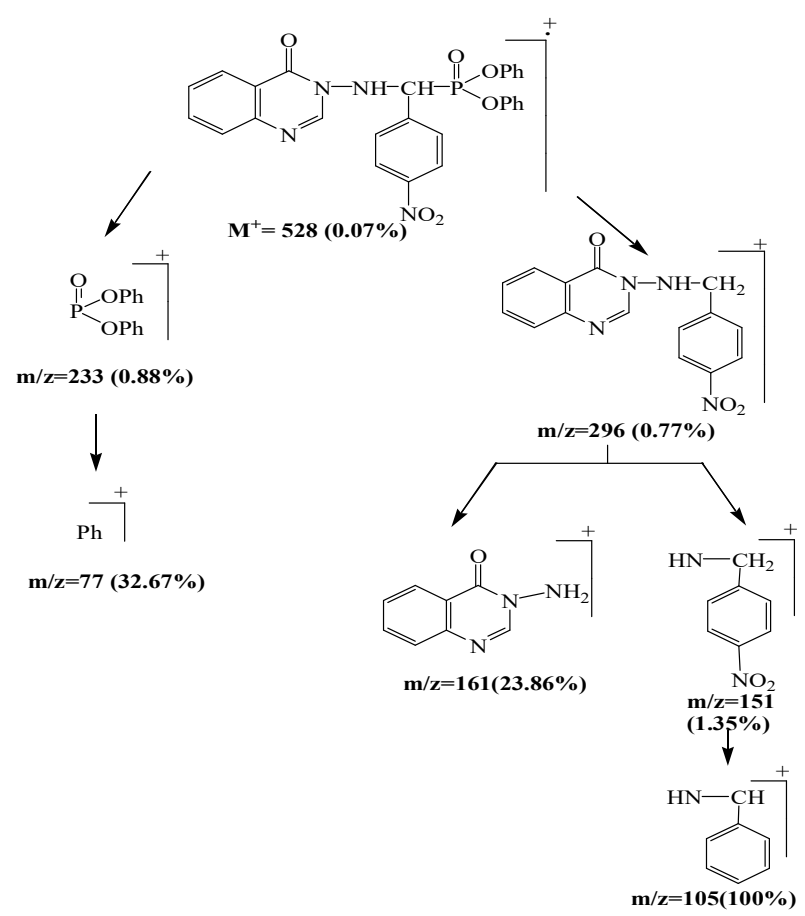

Scheme 3: General fragmentation pathways for compound (2)

Table 1. IR spectral data of $\alpha$-aminophosphonates using 3-amino-4(3H) quinazolinone (1-4)

\begin{tabular}{|c|c|c|c|c|c|c|c|}
\hline \multirow{2}{*}{ Compound } & \multicolumn{7}{|c|}{ Band assignment $\left(\mathbf{v ~ c m}^{-1}\right)$} \\
\cline { 2 - 8 } & $\mathbf{N H} / \mathbf{O H}$ & $\mathbf{C}=\mathbf{O}$ & $\mathbf{C}=\mathbf{N}$ & $\begin{array}{c}\mathbf{C}- \\
\mathbf{C l}\end{array}$ & $\mathbf{P}=\mathbf{O}$ & $\begin{array}{c}\text { P- } \\
\text { O-C }\end{array}$ & $\begin{array}{c}\text { P- } \\
\mathbf{C H}\end{array}$ \\
\hline $\mathbf{1}$ & 3443 & 1693 & 1613 & ---- & 1327 & 1022 & 769 \\
\hline $\mathbf{2}$ & 3445 & 1672 & 1624 & ---- & 1343 & 1017 & 778 \\
\hline $\mathbf{3}$ & 3446 & 1649 & 1603 & ---- & 1357 & 1024 & 755 \\
\hline $\mathbf{4}$ & 3446 & 1675 & 1610 & 689 & 1387 & 1011 & 769 \\
\hline
\end{tabular}

Table $\quad 2 .{ }^{1} \mathrm{H}-\mathrm{NMR}$ spectral data of $\alpha$ aminophosphonates using 3-amino-4(3H) quinazolinone (1-4)

\begin{tabular}{|c|c|c|c|c|}
\hline \multirow[b]{2}{*}{ Compound } & \multicolumn{4}{|c|}{ Type of protons } \\
\hline & $\begin{array}{c}\text { NH } \\
\text { Proton }\end{array}$ & $\begin{array}{l}\text { C-H-P } \\
\text { Proton }\end{array}$ & $\begin{array}{l}\text { Phenyl } \\
\text { group } \\
\text { Protons }\end{array}$ & $\begin{array}{l}\text { Other } \\
\text { Protons }\end{array}$ \\
\hline 1 & $\begin{array}{l}9.29 \\
\text { (s) }\end{array}$ & $\begin{array}{l}5.40 \\
\text { (d) }\end{array}$ & $\begin{array}{c}6.97-8.60 \\
(\mathrm{~m})\end{array}$ & ----- \\
\hline 2 & $\begin{array}{l}9.69 \\
\text { (s) }\end{array}$ & $\begin{array}{l}5.95 \\
\text { (d) }\end{array}$ & $\begin{array}{c}7.55-8.39 \\
(\mathrm{~m})\end{array}$ & ----- \\
\hline 3 & $\begin{array}{l}9.46 \\
(\mathrm{~s})\end{array}$ & $\begin{array}{l}5.30 \\
\text { (d) }\end{array}$ & $\begin{array}{c}6.92-9.01 \\
(\mathrm{~m})\end{array}$ & $\begin{array}{c}10.40 \\
(\mathrm{~s}) \\
(\mathrm{OH})\end{array}$ \\
\hline
\end{tabular}

\begin{tabular}{|l|c|c|c|c|}
\hline $\mathbf{4}$ & $\begin{array}{c}9.35 \\
(\mathrm{~s})\end{array}$ & $\begin{array}{c}5.78 \\
(\mathrm{~d})\end{array}$ & $\begin{array}{c}7.62-8.59 \\
(\mathrm{~m})\end{array}$ & ---- \\
\hline
\end{tabular}

\subsection{Antimicrobial activities}

The antimicrobial activities of the prepared $\alpha$-aminophosphonate compounds were determined against Escherichia coli(NCIM2065), Salmonella $\mathrm{sp}$, salmonella typhimurium, Proteus spas gramnegative bacteria, Staphylococcus aureus (ATCC25292) as gram-positive bacteria and Saccharomyces cerevisiae fungi. The inhibition zones were measured in triplicates and the results of antimicrobial testing are reported in Table 4.The results recorded in ,Table 3 showed that All compounds showed antimicrobial activities against all tested organisms except compound (3) which has no antimicrobial activity against (Escherichia coli, Staphylococcus aureus, and Saccharomycesservices). Also, compound (4) has no antimicrobial activity against Saccharomycesservices. Compound (2) is the most effective compound among all investigated compounds against Staphylococcus aureus, Salmonella typh, and Proteus sp., while compound (1) is the most effective one against Saccharomycesservices and, Salmonella sp. It isalsoclear that substitution on the phenyl ring originated from aryl aldehydes affected on the activity of compounds against the tested organisms (i.e., compounds 2,4 which have electron withdrawing group such as NO2 and Clgroups, respectively, in aryl aldehydes have high activity than $\mathrm{OH}$ group in compound 3 which is electron donating group). From the abovedata,it is concluded that presence of electron withdrawing group increases the biological activity than the presence of the electron donating group. 
Table 3. Antimicrobial activity (inhibition zones $\mathrm{mm}$ ) for $\alpha$-aminophosphonate compounds $1-4$.

\begin{tabular}{|c|c|c|c|c|c|c|}
\hline \multirow[b]{3}{*}{ 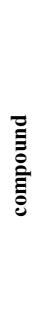 } & \multicolumn{6}{|c|}{ Inhibition Zone diameter ( $\mathrm{mm}$ ) } \\
\hline & \multicolumn{5}{|c|}{ Bacteria } & \multirow{2}{*}{ 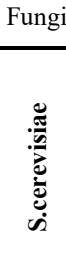 } \\
\hline & $\begin{array}{l}\text { :07 } \\
\text { 되 }\end{array}$ & 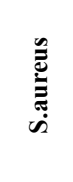 & 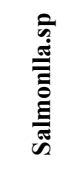 & 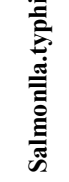 & 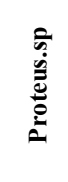 & \\
\hline 1 & $20 \pm 2$ & $20 \pm 1$ & $21 \pm 2$ & $20 \pm 1$ & $20 \pm 2$ & $21 \pm 2$ \\
\hline 2 & $20 \pm 1$ & $21 \pm 3$ & $13 \pm 1$ & $23 \pm 2$ & $22 \pm 1$ & $17 \pm 1$ \\
\hline 3 & ----- & ----- & $17 \pm 3$ & $17 \pm 1$ & $21 \pm 1$ & ----- \\
\hline 4 & $16 \pm 3$ & $18 \pm 2$ & $16 \pm 2$ & $16 \pm 3$ & $21 \pm 2$ & ----- \\
\hline
\end{tabular}

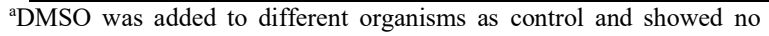
inhibition zone.

\subsection{Minimum inhibitory concentrations (MICs)}

The minimum inhibitory concentrations (MICs) of the synthesized compounds $1-4$, are determined for each antimicrobial agent by using agar diffusion method. The inhibition zone was measured triplicates in different concentrations (2.5, $5,10 \mathrm{mg} / \mathrm{ml}$ ) and the mean value \pm standard deviation (SD) of Minimum inhibitory concentrations (MICs) is tabulated in (Table 4). The reference compound of antibacterial is streptomycin $(\mathrm{MIC}=18 \mu \mathrm{g} / \mathrm{ml})$ and the reference compound of antifungal is mycostatine $(\mathrm{MIC}=18 \mu \mathrm{g} / \mathrm{ml})$. It is shown from table 3 that, all compounds show high antimicrobial activities at low concentrations (2.5 $\mathrm{mg} / \mathrm{mL}$ ) for S.aureus and S.cerevisiae. On the other hand, all compounds have activities at higher concentrations $(5 \mathrm{mg} / \mathrm{ml})$ in the case of E. coli.

Table 4.Minimum inhibitory concentrations (MICs) of $\alpha$-aminophosphonate compounds $1-4^{\text {a }}$

\begin{tabular}{|c|c|c|c|c|}
\hline \multirow{2}{*}{$\begin{array}{c}\text { Compound } \\
\text { no }\end{array}$} & \multicolumn{4}{|c|}{ Minimum inhibitory concentrations (MICs) } \\
\cline { 2 - 5 } & S.aureus & E coli & S.cerevisiae & $\begin{array}{c}\text { Mean } \\
\text { MICs } \\
(\mathrm{mg} / \mathrm{mL})\end{array}$ \\
\hline
\end{tabular}

\begin{tabular}{|c|c|c|c|c|}
\hline 1 & $2.5 \pm 0.5$ & $5 \pm 0.2$ & $2.5 \pm 0.3$ & 3.33 \\
\hline 2 & $2.5 \pm 0.3$ & $5 \pm 0.5$ & $2.5 \pm 0.4$ & 3.33 \\
\hline 3 & $2.5 \pm 0.7$ & $5 \pm 0.3$ & $2.5 \pm 0.5$ & 3.33 \\
\hline 4 & $2.5 \pm 0.2$ & $5 \pm 0.4$ & $2.5 \pm 0.7$ & 3.33 \\
\hline
\end{tabular}

${ }^{\mathrm{a}}$ The standard antibiotics were streptomycin for bacteria $(\mathrm{MIC}=18$ $\mu \mathrm{g} / \mathrm{ml})$ and mycostatine for fungi $(\mathrm{MIC}=18 \mu \mathrm{g} / \mathrm{ml})$.

\subsection{Anticancer activity and $\mathrm{IC}_{50}$ values}

The cytotoxic activity of the tested aminophosphonates 1-4 was investigated by using liver carcinoma cell line (HepG2) which is one of the most common ones in Egypt. The $\mathrm{IC}_{50}$ values were determined as the concentration of tested agents producing $50 \%$ decrease of cell survival. The effect of compounds (1-4)on cell proliferation of human liver carcinoma cell line (HepG2)in vitroare studied, and evaluated by cytotoxic sulforhodamine B (SRB) assay as represented in Fig. 1 (A-D). The reference compound is doxorubicin $\left(\mathrm{IC}_{50}=3 \mu \mathrm{g} / \mathrm{ml}\right)$

$$
\text { [(4-Oxo-4H-quinazolin-3-ylamino) phenyl }
$$
methyl]-phosphoric acid diphenyl ester (1) (Fig. $1 \mathrm{~A}$ ) is proved to be the most active cytotoxic agent amongstthe newly synthesized aminophosphonates, causing $50 \%$ inhibition of cell viability at low micro molar concentrations $(8.18 \mu \mathrm{g} / \mathrm{mL})$. On the other hand, [(4-hydroxyphenyl)-(4-oxo-4Hquinazolin-3-ylamino) methyl]-phosphonic acid diphenyl ester (3) was found to be the least active (Fig. 1C) and exhibited the highest $\mathrm{IC}_{50}$ $(28.8 \mu \mathrm{g} / \mathrm{mL})$. The order of compounds could be arranged according to their anticancer activitiesagainst HepG2 as follows: $1>2>4>3$. 

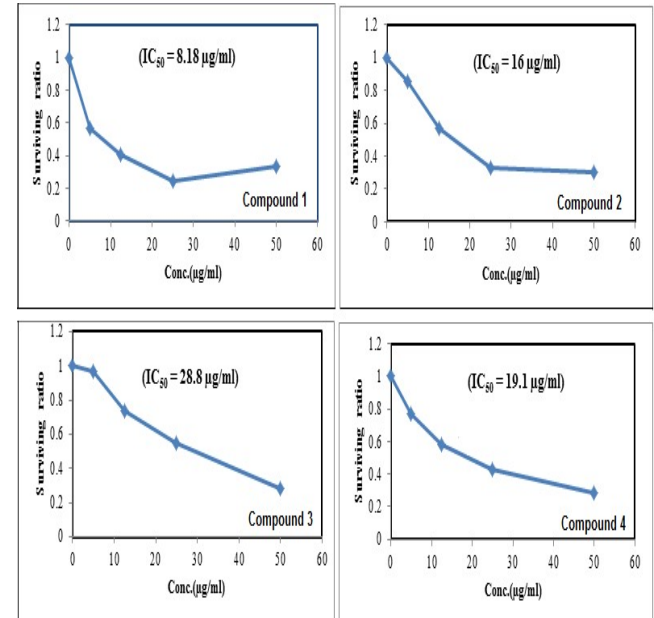

Fig. 1. The effect of various concentrations of $\alpha$ aminophosphonates (1-4) on liver cancer cell line (HepG2).

\subsection{Quantum chemical calculations:}

\subsubsection{Quantum chemical parameters}

The calculated quantum chemical descriptors provide trends in the reactivity and selectivity features of the studied $\alpha$ aminophosphonate compounds. Accordingly, quantum chemical calculations are performed to investigate the effect of structural parameters on the biological activity of $\alpha$-aminophosphonate compounds.

Geometric and electronic structures of the investigated compounds are calculated by optimization of their bond lengths, bond angles and dihedral angles. The optimized molecular structures with minimum energies obtained from the calculations are given in Fig. 2.

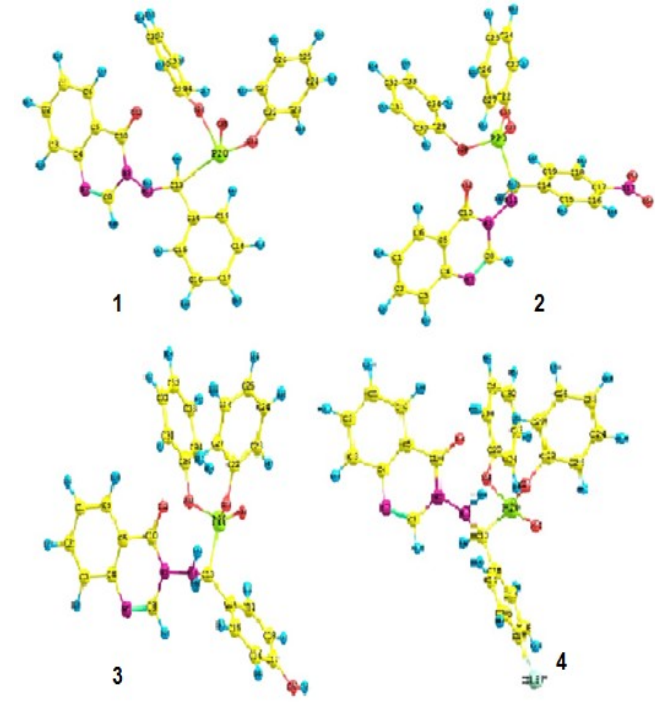

Fig. 2.The optimized structures of the $\alpha$-aminophosphonate compounds using DFT method (using B3LYP basis set).

Quantum chemical parameters are obtained from the DFT calculations which are responsible for the biological activity of $\alpha$-aminophosphonate compounds are collected in Table 6.

Experimentally, the presence of $\mathrm{NO} 2$ group inpara position of the aryl aldehyde moiety of the $\alpha$ aminophosphonate compound instead of $\mathrm{OH}$ group increases the biological activity which could be explained from the calculated quantum chemical parameters. The chemical parameters show that the presence of NO2 decreases the LUMO energy ($3.216 \mathrm{eV}$ ), which means that this compound could react as electrophile (electron acceptor), and accordingly increases its electron affinity, which means that this compound is able to form a hydrogen bond interaction with the enzyme and increases the biological activity of this compound comparable with compound $3(3.216,1.820 \mathrm{eV})$, respectively, Table 5 .

$\Delta \mathrm{E}$ is the function of reactivity, decreasing the value of $\Delta \mathrm{E}$ increasing the reactivity of the 
compounds. The small energy gap between HOMO and LUMO permits the transfer and exchange of electron which leads to an increase the reactivity of the molecules. The calculations show that the compound (2) has the lowest separation energy, $\Delta \mathrm{E}$ among all compounds $(3.532 \mathrm{eV})$, which reflects the highest reactivity of the compound (2) towards the enzyme that agrees well with the experimental data, Table 5.

The polar molecules dissociate better than non-polar molecules whereby the polarity of the molecule is generally expressed in terms of dipole moment (DM). It is a physicochemical property of a drug candidate which is widely used in the medicinal chemistry as an index of lipophilicity and ability of drug molecule for crossing various biological membranes. In general, the solubility of a drug substance in water increases with an increasing in DM. The calculations show that compound (2)hashigher dipole moment value (8.0948 D) than compound (3 (1.7276 D), Table 5. This means that compound (2) is more polarizable (hydrophilic)than compound(3).

Electrophilicity is the descriptor of reactivity and is sufficient enough to describe the toxicity of these molecules. It is also provide the direct relationship between the rates of reactions and the ability to identify the function or capacity of an electrophile and the electrophilic power of the inhibitor. It is shown from the calculations that the compound (2) has the highestelectrophilicity index $(7.027 \mathrm{eV})$ than compound (3) $(3.692 \mathrm{eV})$, which could explain that compound(2) has high ability to react as electrophile and also has high biological activity than compound (3), Table 5.

Softness is a property of molecules that measures the extent of chemical reactivity. The interaction occurs at the part in the molecule which has the highest softness. The calculations showed that the molecule (2) has highersoftnessvaluethan compound (3) (0.566, $0.432 \quad$ e.V-1), respectively,which means that compound (2) could react simply more than compound (3), Table 5.

The maximum amount of electronic charge $(\Delta \mathrm{Nmax})$ acquired from the environment (donor) by inhibitor (acceptor) is a new reactivity index measured the stabilization in energy of the complex. The calculation showthat compound (2) has higher $\Delta \mathrm{Nmax}$ (2.821e) than that of compound (3) $(1.788 \mathrm{e})$, Table 5, which indicates that compound (2) allows the charge transfer and exchange of electron density which increase its reactivity and accordingly increases the biological activity, Table 5 . 


\subsubsection{The frontier molecular orbitals}

Table 5. The alculated quantum chemical parameters of $\alpha$-aminophosphonate compounds.

\begin{tabular}{|c|c|c|c|c|c|c|c|c|c|c|c|c|c|c|c|}
\hline $\begin{array}{l}\bar{\Xi} \\
\text { ڤे } \\
\text { ठे }\end{array}$ & $\begin{array}{c}\text { ЕНОМО } \\
\text { (e.V) }\end{array}$ & $\begin{array}{c}\text { ELUMO } \\
\text { (e.V) }\end{array}$ & $\begin{array}{c}\Delta \mathbf{E} \\
(\mathrm{e} . \mathrm{V})\end{array}$ & $\begin{array}{l}\text { DM } \\
\text { (D) }\end{array}$ & $\begin{array}{c}\text { IP } \\
(\mathrm{e} . \mathrm{V})\end{array}$ & $\begin{array}{c}\text { EA } \\
(\mathrm{e} . \mathrm{V})\end{array}$ & $\begin{array}{c}\eta \\
\text { e.V }\end{array}$ & $\begin{array}{c}\sigma \\
(\mathrm{e} . \mathrm{V}-1)\end{array}$ & $\begin{array}{c}\mu \\
(\mathrm{e} . \mathrm{V})\end{array}$ & $\begin{array}{c}\mathrm{X} \\
(\mathrm{e} . \mathrm{V})\end{array}$ & $\omega$ & $\Delta \mathrm{Nmax}$ & $\begin{array}{c}\text { MV } \\
\text { (cm3/mol) }\end{array}$ & $\begin{array}{c}\text { TNC } \\
\text { (e) }\end{array}$ & $\begin{array}{c}\text { IC50 } \\
(\mu \mathrm{g} / \mathrm{ml})\end{array}$ \\
\hline 1 & -6.501 & -1.831 & 4.669 & 2.2565 & 6.501 & 1.831 & 2.335 & 0.428 & -4.166 & 4.166 & 3.716 & 1.7844 & 334.717 & -9.9801 & 8.18 \\
\hline 2 & -6.748 & -3.216 & 3.532 & 8.0948 & 6.748 & 3.216 & 1.766 & 0.566 & -4.982 & 4.982 & 7.027 & 2.8213 & 349.058 & -10.4664 & 16 \\
\hline 3 & -6.441 & -1.820 & 4.621 & 1.7276 & 6.441 & 1.820 & 2.311 & 0.432 & -4.131 & 4.131 & 3.692 & 1.7880 & 363.752 & -10.5236 & 28.8 \\
\hline 4 & -6.604 & -1.916 & 4.688 & 4.3391 & 6.604 & 1.916 & 2.344 & 0.427 & -4.260 & 4.260 & 3.871 & 1.8167 & 330.089 & -10.3354 & 19.1 \\
\hline
\end{tabular}

The highest occupied molecular orbital

From the above discussion of quantum chemical parameters, it is concluded that the presence of electron withdrawing group such as NO2 group in the $\alpha$-aminophosphonate compound is more favorable for the activity than electron donating group $\mathrm{OH}$ and thisagrees well with the experimental observation.

The replacement of NO2group with $\mathrm{Cl}$ group in para position of the aryl aldehyde moiety of $\alpha$-aminophosphonate compound, increases $\Delta \mathrm{E}$ value by about (1.156 e.V), which decreases the reactivity of compound (4) towards the enzyme. Also, compound (4) has lower electrophilicity index, softness, and dipole moment values than compound (2) by about (3.156 e.V, 0.139 e. $V^{-1}$, $3.756 \mathrm{D})$, respectively, which means that compound (2) is also more reactive than compound (4) towards the enzyme. So that, the quantum chemical parameters improves that the presence of $\mathrm{NO} 2$ group in the synthesized compounds is more effective than the presence of Clgroup which is in a good agreement with the experimental data.
(HOMO) and lowest unoccupied molecular orbital (LUMO) play the key role in molecular interaction. HOMO is the orbital which has ability to donate electrons and its energy corresponds to ionization potential (IP), while LUMO has electrons accepting ability, and its energy corresponds to electron affinity (EA). The charge density distribution of the HOMO and the LUMO levels for the studied molecules are shown in Figs $(3,4)$. The calculation showed that, the HOMO is mainly localized on the two phenyl groups attached to the phosphorous atom except for compound (3) at which the HOMO is mainly localized on one of the phenyl groups attached to phosphorous atom and phenolic moiety (Fig 3). On the other hand, The LUMO is mainly delocalized on the quinazolinone moiety except for compound (2) in which the LUMO concerned on the nitro phenyl moiety (Fig 4). These mean that charge transfer may occur from the nucleophilic sites (two phenyl moiety of phosphorous atom or phenolic moiety in case of compound (3) to the electrophilic part of molecules (quinazolinone ring or nitro phenyl moiety in the case of compound (2)). 


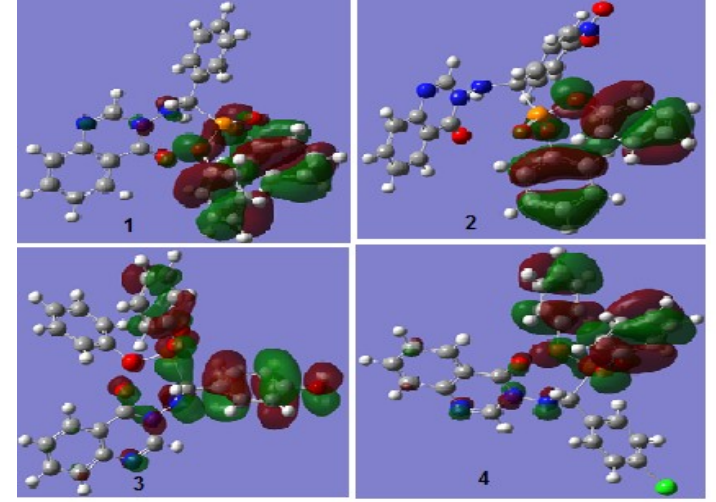

Fig.3.The HOMO molecular orbital of the investigated compounds using DFT method

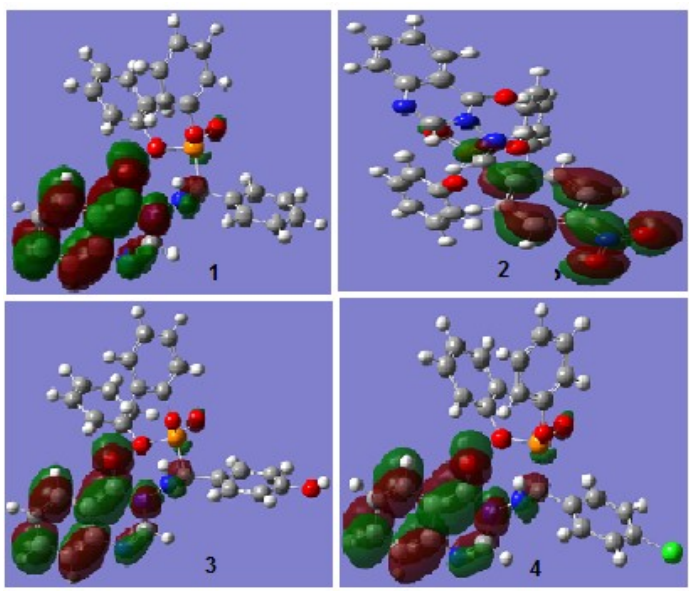

Fig.4.The LUMO molecular orbital of the investigated compounds using DFT method.

2.5.3. Molecular electrostatic potential (MEP-Maps). The molecular electrostatic potential (MEP) was investigated by theoretical calculations at the B3LYP/6-31+G (d) level. Molecular electrostatic potential is related to the electronic density and is a very useful descriptor in understanding sites for electrophilic attack and nucleophilic reactions as well as hydrogen bonding interactions [38-40]. The negative (redcolor) regions of MEP were related to electrophilic reactivity and the positive (blue color) ones to nucleophilic reactivity shown in Fig. 5. The negative regions are mainly concentrated on the Oxygen atom attached to phosphorous group ($\mathrm{P}=\mathrm{O}$ ) and nitrogen atom (N7) of quinazoline ring and the positive regions are mainly concentrated on the other nitrogen atom (N9) of quinazoline ring and phosphorous (P) group. So, Fig. 5confirms the existence of intramolecular and intermolecular interactions observed in the solid state.
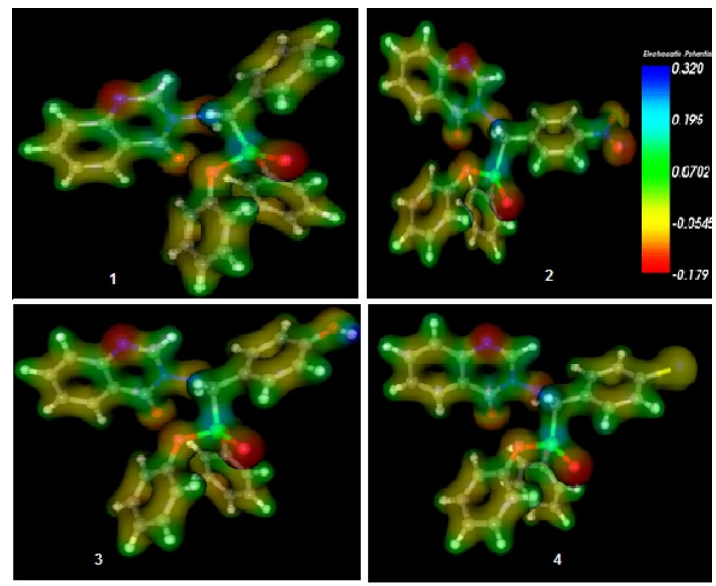

Fig.5. MEP of the $\alpha$-aminophosphonate compounds using DFT method.

\section{Experimental}

\subsection{General experimental}

Melting points were determined by the open capillarymethod using an Electro thermal MEL-TEMP II apparatus andare reported uncorrected. Ft-IR spectra were recorded on a Perkin-Elmer1430 Spectrophotometer using $\mathrm{KBr}$ disk technique. 1H NMRspectrawere measured at Cairo University, Cairo, Egypt on a Bucher AC300 spectrometer operating at $300 \mathrm{MHz}$. The spectra were recorded in dimethyl sulphoxideDMSO-d6, and chemical shifts $\delta$ are reported in parts per million (ppm) relative to TMS. El-Mass spectra for compounds were recorded on a mass spectrometer model 7070 at energy 70 e.v at Cairo University, Cairo, Egypt. . Microanalysis was performed by analytical service at both the Universities of Tanta and Cairo, Egypt.

All samples were examined by analytical thin layer chromatography (TLC). 
3.2. Synthesis of Diphenyl (aryl) (4-oxoquinazolin-4(3H)-ylamino)methylphosphonate 1-4

To a stirred solution of 3-amino-4(3H)quinazolinone $(0.01 \mathrm{~mol}, 1.61 \mathrm{gm})$ and different aldehydes $(0.012 \mathrm{~mol})$ in dry dichloromethane $\mathrm{CH} 2 \mathrm{Cl} 2 \quad(5 \mathrm{~mL})$ at room temperature, triphenylphosphite $(0.01 \mathrm{~mol}, 3.6 \mathrm{ml})$ and cupper trifillateCu(OTf)2 (10 mol \%) were added. The reaction mixture was stirred at room temperature until completion of the reaction as indicated by TLC. Then $\mathrm{CH} 2 \mathrm{Cl} 2$ was evaporated and the $\alpha$ aminophosphonates were precipitated using methanol. The collection of the precipitate by filtration and recrystallization from ethanol to give new pure $\alpha$-aminophosphonate compounds in good yield, Table 6.Table 6 indicated that the reaction represented in Scheme 1 is a general, simple and good yielding reaction to produce various $\alpha$ aminophosphonates.

Table 6. Synthesis of Diphenyl (aryl) (4-oxoquinazolin-4(3H)-yl amino) methylphosphonate 14according to Scheme 1

\begin{tabular}{|c|c|c|c|}
\hline Product & m.p. ( $\left.^{\circ} \mathbf{C}\right)$ & Reaction time $^{\text {a }}$ (hours) & Yield $^{\text {b }}(\mathbf{\%})$ \\
\hline $\mathbf{1}$ & $126-128$ & 36 & 55 \\
\hline $\mathbf{2}$ & $252-254$ & 34 & 60 \\
\hline $\mathbf{3}$ & $221-223$ & 37 & 57 \\
\hline $\mathbf{4}$ & $162-164$ & 38 & 53 \\
\hline
\end{tabular}
'Completion of the reaction was tested by the use of TLC.
b Yield of pure products as colorless crystals after crystallization from
ethanol.

3.2.1. Diphenyl (phenyl) (4-oxo-quinazolin-4(3H)ylamino) methylphosphonate 1

IR (KBr): 3443, 1693, 1613, 1327, 1022, $769 \mathrm{~cm}^{-1}$; 1H NMR (DMSO-d6): $\delta$ 9.29(s, 1H, NH), 5.4 (d, $1 \mathrm{H}, \mathrm{CHP})$, 6.97-8.6 (m, 20H, Ar-H); the mass spectra show molecular ion peak $(\mathrm{M}+)$ at $\mathrm{m} / \mathrm{z}=483$.

3.2.2. Diphenyl (4-nitrophenyl) (4-oxo-quinazolin4(3H)-ylamino) methylphosphonate 2
IR (KBr): 3445, 1672, 1624, 1343, 1017, $778 \mathrm{~cm}^{-1}$; 1H NMR (DMSO-d6): $\delta$ 9.6(s, 1H, NH), 5.9 (d, 1H, CHP), 7.4-8.4 (m, 19H, Ar-H); the mass spectra show molecular ion peak $(\mathrm{M}+)$ at $\mathrm{m} / \mathrm{z}=528$.

3.2.3. Diphenyl (4-hydroxyphenyl) (4-oxo-quinazolin4(3H) -ylamino) methylphosphonate 3

IR (KBr): 3446, 1649, 1603, 1357, 1024, $755 \mathrm{~cm}^{-1}$; 1H NMR (DMSO-d6): $\delta$ 9.48(s, 1H, NH), 5.3 (d, 1H, CHP), 7-8.8 (m, 19H, Ar-H), 10.4 (s, H, OH).

\subsubsection{Diphenyl(4-chlorophenyl)(4-oxo-quinazolin4}

(3H) -ylamino) methylphosphonate 4

IR (KBr): 3446, 1675, 1610, 1387, 1011, $769 \mathrm{~cm}^{-1}$; 1H NMR (DMSO-d6): $\delta 9.4$ (s, 1H, NH), 5.8 (d, 1H, CHP), 7.6-8.6 (m, 19H, Ar-H).

\subsection{Antimicrobial activities}

\subsubsection{Test microorganisms}

\subsubsection{Gram-negative bacteria.}

After Gram-staining procedure, Gramnegative cells appear pink. The Gram-negative bacteria used in this study were E. coli, Salmonella sp, Salmonella typhimurium, and Proteus sp..E. coli is known as the back bone example for Gramnegative bacteria and cause urinary infection, wound infection and gastroenteritis.

\subsubsection{Gram-positive bacteria.}

A Gram-positive bacterium used in this study is S. aureus which is the mild stoneof Grampositive bacteria and it is a causative agent of pneumonia, meningitis and food poisoning.

\subsubsection{Fungi.}

An example of pathogenic strains of fungi is S. cerevisiae. The tested organisms were obtained from the culture collection of Bacteriology Unit, Department of Botany, Faculty of Science, TantaUniversity, Egypt.

\subsubsection{Media used and antimicrobial assay.}


Nutrient and Sabouraud's broths, Nutrient and Sabouraud's agar were used for growing and maintaining the tested bacteria and yeast, respectively. The antimicrobial spectrum of the synthetic compounds is determined as powdered samples by the cut-plug method on plates seeded with the tested bacteria (E. coli, Salmonella sp, Salmonella typhimurium, and Proteus sp.) on nutrient agar, which contained per liter: peptone (3 g), beef extract (5 g), $\mathrm{NaCl}(5 \mathrm{~g})$ and agar $(20 \mathrm{~g})$ at $\mathrm{pH}$ 7. The test was also performed on plates seeded with S. cerevisiae,Sabouraud's agar that contained per liter: glucose $(40 \mathrm{~g})$, peptone $(10 \mathrm{~g})$ and agar $(20 \mathrm{~g})$ at $\mathrm{pH}$ 6.0. After solidification, the wells are made and each was filled with powdery compounds (10 mg). The plates are then incubated at $30^{\circ} \mathrm{C}$ for 24-48 h, after which the diameters of the inhibition zones are measured. Compounds which produced the highest inhibition zonesare selected and assayed further at different concentrations in suspensions to quantify their inhibitory effects. Nutrient and Sabouraud's broths were used in activation of organisms [41].

\subsubsection{Determination of minimum inhibitory concentrations (MICs)}

The antimicrobial activity is checked to determine the (MICs) by using agar diffusion method. The culture is drawing in nutrient broth for bacteria and sabroud broth for fungi and incubated at $37 \mathrm{oC}$ for 24 hours. After incubation period is over, the optical density of the culture is adjusted to 0.1 with sterile broth, and $20 \mathrm{ml}$ of agar is poured into sterile Petri plates and allowed to solidify. A series from different dilutions of synthetic compounds by the following: $(2.5,5,10 \mathrm{mg} / \mathrm{ml}$ from DMSO. Also, about $(100 \mu \mathrm{l})$ of DMSO is used as control without any synthetic compounds. The disks $(0.5 \mathrm{~mm}$ diameter) impregnated with $(100 \mu \mathrm{l})$ of respective synthetic compounds are placed on the surface of the Petri plates seeded with $(0.1 \mathrm{ml}$ of microbial suspension $(5 \times 105 \mathrm{cfu} / \mathrm{ml}$ for bacteria and $4 \times 104 \mathrm{cfu} / \mathrm{ml}$ for fungi). Soon afterwards, the plates are kept at $10 \mathrm{oC}$ for 30 minutes and normalized to room temperature; the plates are incubated at $37^{\circ} \mathrm{C}$ for 24 hours. The antimicrobial activities of the tested samples are determined by measuring the diameter of zone of inhibition expressed in millimeter. The inhibition zones are measured in triplicatesand expressed as mean \pm SD [42].

\subsection{Anticancer activities}

In vitro potential cytotoxicities of the synthesized compounds are tested using the colorimetric method. Cytotoxic activity of $\alpha$ aminophosphonate 1-4 are tested against cancer cells $(5 \mathrm{mg} / \mathrm{mL}$ in DMSO), obtaining medium inhibitory concentration(IC50) values in $\mathrm{g} / \mathrm{mL}$, using a dilution method in a 96-well plate. After 72 $\mathrm{h}$ incubation, absorbance is measured at $546 \mathrm{~nm}$. DMSO was used as negative control and Doxorubicin (DOX) as positive control, both at the same concentration as the synthesized compounds.Compounds(1-4)are dissolved in DMSO and subjected to cytotoxic evaluation against two cancer cell lines namely liver carcinoma cell line (HepG2). 3-(4, 5Dimethylthiazol-2-yl)-2,5-diphenyltetrazolium bromide is dissolved in saline to make a concentration of $5 \mathrm{mg} / \mathrm{mL}$ as a stock solution. Cancer cells $(5 \times 105$ cells $)$ suspended in $200 \mathrm{lL}$ of MEM medium containing $10 \%$ fetal calf serum were seeded into a 96 well culture plate. After $24 \mathrm{~h}$ of preincubationat $37^{\circ} \mathrm{C}$ in a humidified atmosphere of $5 \% \mathrm{CO} 2$ to allow cell attachment, various 
concentrations of tested solution $(0,12.5,25$, and $50 \mathrm{lg} / \mathrm{mL}$ ) are added and then incubated for $72 \mathrm{~h}$ under the above conditions. At the end of the incubation, $501 \mathrm{~L}$ of tetrazolium reagent is added to each well and then incubated at $37^{\circ} \mathrm{C}$ for $4 \mathrm{~h}$. The supernatant is decanted and DMSO (100 IL) is added to allow Formosansolubilization. The optical density (OD) of each well is detected by ELIZA microplate reader (Meter tech. R 960, USA) at 564 $\mathrm{nm}$. Each determination represents the mean of four replicates. The $50 \%$ inhibition concentration $\left(\mathrm{IC}_{50}\right)$ is determined by curve fitting [43].

\section{Conclusion:}

A convenient method for the synthesis ofDiphenyl (aryl) (4-oxo-quinazolin-4(3H)-yl amino) methyl phosphonate compounds(1-4) was developed. The newly synthesized compounds exhibit a remarkable inhibition of the growth of Gram-positive, Gram-negative bacteria and fungi at low concentrations. The cytotoxicity of the synthesized compounds showed a significant cytotoxicity against the liver cancer cell line (HepG 2). Also, it was shown from the quantum chemical calculations that the electron-withdrawing substituent increases the biological activity of the $\alpha$ aminophosphonate compounds more than the electron donating group which is in a good agreement with the experimental results. Finally, the quantum chemical parameters confirmed with MEPs are able to describe the biological activity of the investigated compounds.

\section{References}

[1] Spirkova K., Stankovsky S., Mrvova A., Cipak L., Chem. Pap.53(1999)272.

[2] Kumar A., Tyagi M., Shrivastava V.K., Indian J. Chem., 42(2003)2142.

[3] Chandrika P.M., Yakaiah T., Rao A.R.R., Narsaiah B., ChakraReddy N., Sridhar V., Rao J.V, Eur. J. Med. Chem., 43(2008)846.
[4] Shah B.R., Bhatt J.J., Patel H.H., Undavia N.K., Trivedi P.B., Desai N.C. , Indian J. Chem. , 34(1995)201.

[5] Rani P., Archana S.V.K., Kumar A., Ind. J. Heterocycl. Chem., 41 (2002) 2642.

[6] Alagarsamy V., Muthukumar V., Pavalarani N., Vasanthanathan P., Revathi R., Biol. Pharm. Bull.,26(2003)557.

[7] Pandey V.K., Sarah T., Zehra T., Indian J. Chem., 43(2004)180.

[8] Joshi V., Chaudhari R.P., Indian J. Chem., 28(1987)602.

[9] Wasfy A.A.F., Indian J. Chem., 42(2003)3102.

[10] Nanda A.K., Ganguli S., Chakraborty R., Molecules, 12(2007)2413.

[11] Shivram H. B., Padmaja M.T., ShivnandaM.K.,Akbarali P.M., Indian J. Chem., 37(1998)715.

[12] Hosseini S. M., J. Iran. Chem. Soc., 5(2008)118.

[13] Reddy M.V.N.,Annar S., Balakrishna A., Reddy G.C.S., Reddy C.S., Org. Commun. 3(2010)39.

[14] Rao A.J.,Rao P.V.,Rao V.K., Mohan C.,RajuC.N., Reddy C.S., Bull. Korean Chem. Soc. 31(2010)1863.

[15] Reddy M.V.N., Kumar B.S.,Balakrishna A., Reddy C.S.,Nayak S.K., Reddy C.D., ARKIVOC15(2007)46.

[16] Rezaei Z.,Firouzabadi H.,Iranpoor N.,Ghaderi A.,JafariM.R.,JafariA.A.,Zare H.R., Eur. J. Med. Chem. 44(2009)4266.

[17] Rao X., Song Z., He L., Heteroatom Chem. 19(2008)512.

[18] Kraicheva I.,Bogomilova A.,Tsacheva I.,Momekov G.,TroevK., Eur. J. Med. Chem. 44(2009)3363.

[19] Xu Y., Yan K., Song B., Xu G., Yang S.,Xue W., Hu D., Lu P.,Ouyang G., Jin L.,ChenZ.,Molecules 11(2006)666.

[20] Du S.,Faiger H.,Belakhov V.,Baasov T., Bioorg. Med. Chem. 7(1999)2671.

[21] Giannousis P.P, Bartlett P.A.,J. Med. Chem. 30(1987)1603.

[22] Allen M.C., Fuhrer W., Tuck B., Wade R.,WoodJ.M. Renin inhibitors. , J. Med. Chem. 32(1989)1652; Molecules 15 (2010) 8211.

[23] Boyd. D.B., VCH Publishers, 1(1990)355.

[24] Balbes L., Mascarella S., and Boyd D., VCH Publishers, 5(1994)337. 
[25] ProftF.D.,GeerlingsP, Chem. Rev. 101(2001)1451.
[43] Skehan P.,Storeng R., Scudiero D., Monks A., McMahon J.,Vistica D.,

WarrenT. W.,BokeschH., Kenney S., BoydM. R., J. Natl. Cancer Inst. 82(1990)1107.

[26] DicksonR.M.,BeckeA.D., J. Chem. Phys. 99(1993)3898; JohnsonB.G. GillP.M.W.,PopleJ.A., J. Chem. Phys. 98(1993)5612.

[27] Wang Q. M., Li Z. G., Hung R. Q., Cheng J. R., Heteroatom Chem. 12(2001)68.

[28] BeckeA.D., J. Chem. Phys. 96(1992)9489.

[29] BeckeA.D., J. Chem. Phys. 98(1993)1372.

[30] LeeC.,YangW., ParrR.G., Phys. ReV. B 37(1988)785.

[31] FrischM.J., et al., Gaussian 03, Revision B.01, Gaussian, Inc., Pittsburgh, PA, (2003).

[32] ParrR.G.,DonnellyR.A., LevyM., PalkeW.E., J. Chem. Phys. 68(1978)3801.

[33] ParrR.G.,PearsonR.G., J. Am. Chem. Soc. 105(1983)7512.

[34] PearsonR.G.,Inorg. Chem. 27(1988)734.

[35] GeerlingsP., De ProftF., LangenaekerW., Chem. Rev. 103(2003)1793.

[36] AwadM.K.,IssaR.M., AtlamF.M., Mater. Corros. 60(2009)813.

[37] AwadM.K.,MahgoubF.M., El-iskandaraniM.M., J. Mol. Struct. (THEOCHEM) 531(2000)105.

[38] ScroccoE.,TomasiJ., Adv. Quantum Chem. 11(1978)115.

[39] LuqueF.J.,LopezJ.M., OrozcoM., Theor. Chem. Acc. 103(2000)343.

[40] OkulikN.,JubertA.H., Internet electron, J. Mol. Des. 4(2005)17.

[41] Pridham T. G.,Lindenfelser L. A., Shotwell O. L.,Stodola F.,BenedictR. G.,Foley C., Jacks P. W.,Zaumeeyer W. J.,Perston W. H., Mitchell J. W. , Phytopathology 46(1956) 568.

[42] Hsueh P. R., Chang J. C., Teng L. J., Yang P. C., Ho S. W.,HsiehW. C., Luh K. T.,J. Clin. Microbiol. 35(1997)1021. 


\section{دراسة النشاط البيولوجى كمضاد للسرطان والميكروبات ودراسات نظرية دالة الكثافة لمركبات الألفا أمينوفوسفونات المخلقة من الأمينو كوينازولين}

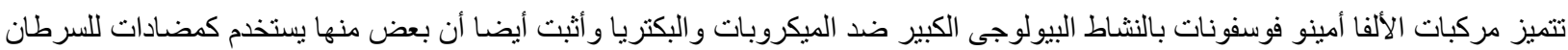

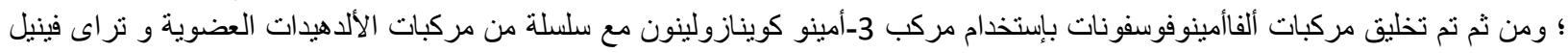

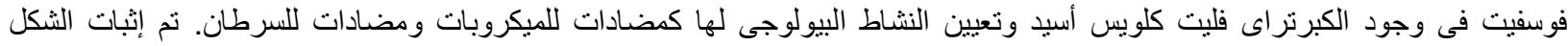

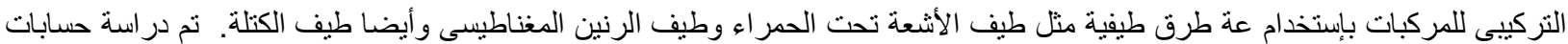

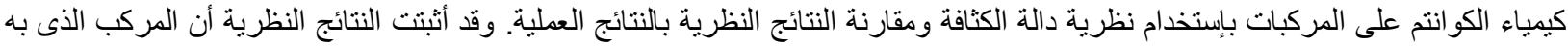
مجمو عة ساحبة يكون أكثر نشاطا عن المركب الذى يحتوى على مجموعة معطية مما يتفق مع النتائج العملية. 